\title{
Voice Handicap Index and Vocal Characteristics of Teachers
}

\author{
Sang-Ah Lee ${ }^{1}$, Hyun Ju Choi ${ }^{2}$, Bom Kim ${ }^{1}$, HeyJean Lee ${ }^{3}$, \\ Soek Ki Lee ${ }^{4}$, Jong Gag Lee and Eui-Cheol Nam ${ }^{4}$ \\ ${ }^{I}$ Department of Preventive Medicine, Kangwon National University School of Medicine, Chuncheon; and \\ ${ }^{2}$ Hyun Ju Choi Speech-Language Center, Chuncheon; and \\ ${ }^{3}$ Department of Preventive Medicine, Kangwon National University Hospital, Chuncheon; and \\ ${ }^{4}$ Department of Otolaryngology, Kangwon National University School of Medicine, Chuncheon; and \\ ${ }^{5}$ Department of Education, College of Education, Kangwon National University, Chuncheon, Korea
}

\section{교사들의 음성장애지수와 음성의 음향학적 특성}

이상아 ${ }^{1} \cdot$ 최현주 $^{2} \cdot$ 김 봄 $^{1} \cdot$ 이혜진 ${ }^{3} \cdot$ 이석기 $^{4} \cdot$ 이종각 $^{5} \cdot$ 남의철 $^{4}$

강원대학교 의학전문대학원 예방의학교실, ${ }^{1}$ 최현주 언어치료센터, ${ }^{2}$ 강원대학교병원 예방의학과, ${ }^{3}$

강원대학교 의학전문대학원 이비인후과학교실, ${ }^{4}$ 강원대학교 사범대학 교육학과 ${ }^{5}$

Received November 26, 2011

Revised December 12, 2011

Accepted December 19, 2011

Address for correspondence

Eui-Cheol Nam, MD, PhD

Department of Otolaryngology,

Kangwon National University

School of Medicine,

1 Gangwondaehak-gil,

Chuncheon 200-701, Korea

Tel $+82-33-258-2311$

Fax $+82-33-255-8809$

E-mail birdynec@kangwon.ac.kr
Background and Objectives The effect of vocal abuse on school teachers' lives has not been sufficiently studied in Korea. Our goal was to investigate teachers' vocal characteristics and their functional, physical and emotional disorders due to vocal abuse, and the correlation between them.

Subjects and Method Voice samples of 142 school teachers who responded to the Voice Handicap Index (VHI) questionnaire were used for the acoustic analysis. The results were compared with the control group of 27 office workers of our hospital, who matched the experimental group with respect to age and sex.

Results The subjective measure of VHI showed that the teacher handicap indices were significantly higher than those of the control group in functional, physical and emotional aspects: the corresponding median values were $8,10,4.5$ and 2, 3, 1 for the two groups, respectively $(p<0.05)$. There was no difference in jitter, shimmer and signal-to-noise ratio between the groups. A cross-correlation analysis revealed no significant correlation between VHI-scores and the results of acoustic analysis.

Conclusion The teachers recognize their voice problems as a serious physico-functional disorder. However, the acoustic analysis of the 2 second-voice samples could not detect any differences in voice quality between the two groups. There was no significant correlation between VHI scores and acoustic measures. It suggests that the acoustic measures of voice samples with a limited duration might have a restrictive value in presenting handicaps associated with voice abuse. Korean J Otorhinolaryngol-Head Neck Surg 2012;55:101-6

Key Words Teachers - Voice Handicap Acoustic.

\section{서 론}

직업적으로 음성의 사용이 과다할 수 밖에 없는 교사, 가수, 목사, 전화 교환수 등은 아주 빈번하게 음성장애의 위험에 노
출되어 있다. 특히, 교사들은 음성 사용량이 다른 직업군에 비 해 많고 고정적이며, 음성 사용에 업무를 거의 전적으로 의존 하는 상황이다. 이런 이유들로 인해 최근 직업적 음성장애의 위 험에 노출되어 있는 가장 대표적인 집단으로 교사들을 지목하 
고 있다. ${ }^{1)}$ 미국의 교사 2531명을 대상으로 한 연구에서 교사의 음성장애 빈도가 조사시점에서 약 $11 \%$ 로 대조군(6.2\%)보다 유의하게 높고, 평생 음성장애를 겪는 빈도는 $57.7 \%$ 이며 이로 인해 병원이나 언어치료 시설을 찾는 경우가 $14.3 \%$ 로 조사된 바 있다. ${ }^{2)}$

현재 우리나라 교사는 공립학교 약 45만 명에 사립학교를 합 하면 100 만 명이 넘는 거대 직업군을 형성하며 전체 공무원의 절반이 교사이다. 그러나 교사들의 업무수행 능력과 일상생활 의 장애에 관련된 음성과용에 기인한 장애(handicap, not disability)에 대한 연구는 극히 부족하고 교사들을 포함한 직업적 음성 문제의 평가 방식에 대한 논의도 거의 이루어진 바가 없 다. ${ }^{3)}$ 본 연구에서는 142 명의 현역 교사들을 대상으로 주관적 음 성장애의 정도를 평가하는 음성장애지수(voice handicap in$\mathrm{dex}, \mathrm{VHI}$ ) 설문조사와 음성 샘플의 객관적인 음향분석을 통해 교사들이 음성과용으로 인해 겪는 장애의 정도와 음성의 실제 특성을 조사하고 그 사이의 상관관계를 알아보고자 하였다.

\section{대상 및 방법}

\section{대 상}

교사군은 춘천지역에 소재한 6개 학교(초등학교 2, 중학교 3, 고등학교 1)에서 현재 매일 수업을 진행하는 142 명의 교사 (25 62세, 남자 42명, 여자 100명)들로, 대조군은 강원대학교
병원에 근무하는 직원 중 업무상 환자나 보호자를 대하지 않 는 일반 사무직 근로자 27명(20 57세 남자 11명, 여자 16명) 으로 구성하였다(Table 1).

\section{방 법}

\section{음성장애지수 설문조사(VHI-questionnaire)}

음성장애지수(VHI) 설문은 스스로 느끼는 음성장애의 자각 정도에 관한 3 개 영역, 즉, 기능적(functional), 신체적(physical), 정서적(emotional) 영역으로 구성되어 있으며, 각 영역은 음성 문제로 인한 사회생활의 장애, 신체적 장애(증상), 정서심리적 장애를 각각 평가하였다(Table 2). 각 영역은 10 개 문항 으로 이루어져 있으며, 각 문항에 대해 0 (장애를 느끼지 않음) 4(항상 장애를 느낌)의 점수 중 한 개를 선택하며 합산된 점 수가 클수록 주관적으로 자각하고 있는 장애의 정도가 심하다 는 것을 의미하였다. ${ }^{4)}$ 설문 문항은 2007년 타당성과 신뢰도가 검증된 번역본을 기반으로 하였으나 이해를 돕기 위해 문구의 일부를 수정하여 사용하였다. ${ }^{5)}$ 설문조사는 학교와 병원을 직접 방문하여 설문지 배포 후 완성된 설문지를 그 자리에서 수거하 는 방식으로 진행되었다. 교사군에 배포한 설문 170부 중 142 부 (84\%)가 회수되었고 142명 모두 음성분석에 응하였으며, 대조 군의 응답률은 34 명 중 27 명(79\%)이었다.

Table 1. Comparison of sociodemographic characteristics and health behaviors related to voice between teacher-group and control group

\begin{tabular}{|c|c|c|c|}
\hline & Teachers & Control & $n-5 a t u$ \\
\hline & $\mathrm{n}(\%)$ & $\mathrm{n}(\%)$ & p-value \\
\hline Age (year) & & & 0.0894 \\
\hline $20-29$ & $11(7.75)$ & $4(14.8)$ & \\
\hline $30-39$ & $50(35.2)$ & $12(44.4)$ & \\
\hline $40-49$ & $56(39.4)$ & $4(14.8)$ & \\
\hline$\geq 50$ & $25(17.6)$ & $7(25.9)$ & \\
\hline Gender & & & 0.2518 \\
\hline Male & $42(29.6)$ & $11(40.7)$ & \\
\hline Female & $100(70.4)$ & $16(59.3)$ & \\
\hline Excess usage of voice & & & 0.9715 \\
\hline No & $110(77.5)$ & $21(77.8)$ & \\
\hline Yes & $32(22.5)$ & $6(22.2)$ & \\
\hline Cigarette smoking & & & 0.6225 \\
\hline No & $121(85.2)$ & $22(81.5)$ & \\
\hline Yes & $21(14.8)$ & $5(18.5)$ & \\
\hline Alcohol & & & 0.4266 \\
\hline No & $110(77.5)$ & $19(70.4)$ & \\
\hline Yes & $32(22.5)$ & $8(29.6)$ & \\
\hline Total subjects & 142 & 27 & \\
\hline
\end{tabular}

Excess usage of voice: any voice usage, not related with work over 1 hour/week, including singing, counseling, lecturing...etc 
Table 2. Voice handicap indices in the teacher-group and the control-group

\begin{tabular}{|c|c|c|c|}
\hline & \multicolumn{2}{|c|}{ Median $($ mean $\pm S D)$} & \multirow{2}{*}{$\begin{array}{c}\text { Rank sum test } \\
\text { (p-value) }\end{array}$} \\
\hline & Teachers & Control & \\
\hline \multicolumn{4}{|l|}{ 기능적(functional) 영역 } \\
\hline $\mathrm{Fl}$. 사람들이 내 음성을 들을 때 힘들어한다. & $1(1.063 \pm 0.83)$ & $0(0.556 \pm 0.97)$ & $0.0009 *$ \\
\hline F2. 사람들이 시끄러운 상황에서 내 말을 이해하는 데 어려워한다. & $1(1.296 \pm 0.96)$ & $1(0.704 \pm 0.82)$ & $0.0023^{*}$ \\
\hline F3. 집에서 가족 중 누군가를 불렀을 때, 그들은 내 말소리를 알아듣는 데 힘들어한다. & $1(0.824 \pm 0.79)$ & $0(0.444 \pm 0.80)$ & $0.0062^{*}$ \\
\hline F4. 나는 비교적 전화로 애기하는 것을 자제한다. & $1(0.880 \pm 0.95)$ & $0(0.704 \pm 0.87)$ & 0.3560 \\
\hline F5. 난 내 음성 때문에 많은 사람들을 만나는 것을 피한다. & $0(0.423 \pm 0.67)$ & $0(0.074 \pm 0.27)$ & $0.0048^{*}$ \\
\hline F6. 난 내 음성 때문에 친구들, 이웃들, 친척들과 애기하는 것을 삼간다. & $0(0.387 \pm 0.62)$ & $0(0.185 \pm 0.40)$ & 0.1266 \\
\hline F7. 상대방과 대화를 할 때, 내가 한 말을 다시 반복하도록 요구한다. & $1(0.761 \pm 0.82)$ & $0(0.630 \pm 0.93)$ & 0.2728 \\
\hline F8. 나는 나의 음성으로 인해 성격이나 사회적인 삶에 좋지 않은 영향을 준다. & $0(0.500 \pm 0.72)$ & $0(0.222 \pm 0.42)$ & 0.0718 \\
\hline F9. 나는 내 음성으로 인해 사람들과의 대화에서 소외되는 느낌을 가진다. & $0(0.415 \pm 0.68)$ & $0(0.222 \pm 0.42)$ & 0.2083 \\
\hline $\begin{array}{l}\text { F10. 내 음성에 문제가 발생했을 경우, 나의 직업적인 문제(경제적인 문제)에 } \\
\text { 직접적인 영향을 미친다. }\end{array}$ & $2(1.859 \pm 1.53)$ & $0(0.186 \pm 0.48)$ & $<0.0001^{*}$ \\
\hline \multicolumn{4}{|l|}{ 신체적(physical) 영역 } \\
\hline P1. 나는 말을 하고 나면 숨이 차다(공기를 모두 내쉰다). & $1(0.972 \pm 0.93)$ & $0(0.556 \pm 0.80)$ & $0.0229 *$ \\
\hline P2. 나의 음성은 하루 종일 다양하게 변화한다. & $1(1.007 \pm 0.81)$ & $0(0.481 \pm 0.75)$ & $0.0011^{*}$ \\
\hline P3. 사람들이 나에게 “당신 음성에 뭔가 문제가 있는 것 같군요"라고 한다. & $0(0.669 \pm 0.86)$ & $0(0.222 \pm 0.51)$ & $0.0056^{*}$ \\
\hline P4. 내 음성은 삐걱거리거나 마른 느낌이 난다. & $1(1.035 \pm 1.20)$ & $0(0.556 \pm 0.85)$ & $0.0186^{*}$ \\
\hline P5. 나는 목소리를 낼 때, 목이 조이는 듯한 느낌을 갖는다. & $1(0.965 \pm 0.93)$ & $0(0.444 \pm 0.70)$ & $0.0055^{*}$ \\
\hline P6. 내 목소리의 명료도는 예측할 수 없다(자주 변한다). & $1(0.965 \pm 0.82)$ & $0(0.519 \pm 0.70)$ & $0.0079 *$ \\
\hline P7. 나는 다른 방법으로 음성을 내보려고 노력한다. & $1(0.923 \pm 0.89)$ & $0(0.519 \pm 0.94)$ & $0.0103^{*}$ \\
\hline P8. 나는 말을 할 때 힘들게 하는 편이다. & $1(1.085 \pm 0.99)$ & $0(0.370 \pm 0.84)$ & $<0.0001^{*}$ \\
\hline P9. 내 목소리(음성)는 저녁에 더욱 나빠진다. & $1(1.352 \pm 1.05)$ & $0(0.407 \pm 0.75)$ & $<0.0001^{*}$ \\
\hline P10. 말하는 중간에 목소리(음성)가 작아진다(약해진다). & $1(1.155 \pm 0.95)$ & $0(0.667 \pm 0.83)$ & $0.0108^{*}$ \\
\hline \multicolumn{4}{|l|}{ 정서적(emotional) 영역 } \\
\hline El. 내 목소리의 문제로 인해 사람들과 애기할 때 긴장된다. & $0.5(0.711 \pm 0.87)$ & $0(0.481 \pm 0.94)$ & 0.0643 \\
\hline E2. 사람들이 내 목소리에 대해 짜증스러워 하는 것 같다. & $1(0.676 \pm 0.78)$ & $0(0.296 \pm 0.61)$ & $0.0072^{*}$ \\
\hline E3. 사람들이 내 목소리를 이상하게 생각하는 것 같다. & $1(0.718 \pm 0.82)$ & $0(0.333 \pm 0.68)$ & $0.0086^{*}$ \\
\hline E4. 목소리 문제로 인해 나는 화가 난다. & $1(0.838 \pm 1.01)$ & $0(0.296 \pm 0.54)$ & $0.0065^{*}$ \\
\hline E5. 목소리 문제로 인해 스트레스를 받는다. & $1(0.915 \pm 1.03)$ & $0(0.222 \pm 0.42)$ & $0.0004^{*}$ \\
\hline E6. 목소리 문제 때문에 나는 소심해진다. & $0(0.655 \pm 0.83)$ & $0(0.481 \pm 0.85)$ & 0.1750 \\
\hline $\begin{array}{l}\text { E7. 사람들이 대화 중에 내가 한 말을 잘 알아듣지 못하고 다시 한 번 반복하라고 } \\
\text { 했을 때 난 괴롭다. }\end{array}$ & $0.5(0.648 \pm 0.77)$ & $0(0.333 \pm 0.62)$ & $0.0304^{*}$ \\
\hline $\begin{array}{l}\text { E8. 사람들이 대화 중에 내가 한 말을 잘 알아듣지 못하고 다시 한 번 반복하라고 } \\
\text { 했을 때 난 부끄러워진다. }\end{array}$ & $0(0.585 \pm 0.75)$ & $0(0.333 \pm 0.62)$ & 0.0778 \\
\hline E9. 목소리 문제로 인해 나 자신이 무능력하게 느껴진다. & $0(0.521 \pm 0.72)$ & $0(0.148 \pm 0.36)$ & $0.0081^{*}$ \\
\hline E10. 나는 내 음성문제를 부끄럽게 생각한다. & $0(0.521 \pm 0.78)$ & $0(0.259 \pm 0.66)$ & $0.0428^{*}$ \\
\hline
\end{tabular}

\section{음성의 음향학적 분석(Acoustic analysis)}

음성 샘플의 녹음도 학교와 병원을 직접 방문하여 이루어졌 다. 아무도 없는 조용한 방에서 약 $10 \mathrm{~cm}$ 거리를 두고, 평상시 의 편안한 크기로 5 초간 '아를 지속적으로 발성하도록 하여 얻 은 음성 샘플을 Dr. Speech(version 4.4, Tiger DRS, Inc., Seattle, WA, USA)를 사용하여 분석하였다. 2회 반복 녹음하여 그 중 평상시 음성에 가까운 것을 골라 스펙트럼상에서 가장 안정적인 2초의 연속된 구간을 선택하여 분석하였다. Dr. Speech에 내재된 음성 평가(vocal assessment)의 알고리듬을
이용하여 산출된 주파수변동률(jitter), 진폭변동률(shimmer), 신호잡음비(SNR, signal-to-noise ratio)를 측정하였다.

음성장애지수와 음향분석 결과에 따른 음성장애의 빈도를 각각 다음과 같이 산출하였다. 대조군 VHI 점수 총합의 상위 95\%를 초과하는 경우를 주관적 음성장애로 판정하였고, 음향 분석 결과에서는 정상의 기준을 jitter $\leq 0.5$, shimmer $\leq 3.0$, $\mathrm{SNR} \geq 10$ 으로 하여 그 중 1항목 이상이 정상 범위밖에 있는 경우를 객관적 음성장애로 판정하였다. 


\section{통계분석}

통계학적 검증은 대조군 27명 집단의 측정값이 정규분포를 이루지 않았으므로 두 집단 간의 음성장애지수 각 항목별 및 영역별 비교와 음향학적 분석결과의 비교에 비모수적 방법인 Rank sum test를 사용하였고, 각 집단의 대표값은 중앙값(median value)으로 표현하였다. 교사군과 대조군 사이에 인구-사 회적 요소 비교와 음성장애 빈도의 비교에는 Chi-square test 를 사용하였다. 음성장애지수와 음향학적 변수 사이의 관련성 을 알아보기 위해 상관성 분석(Spearman correlation coefficient)을 조사하였다. 통계분석은 SAS-package version 9.1 프 로그램을 이용하였다. 본 연구는 본원의 임상시험윤리위원 회의 심의를 통과하였다.

\section{결 과}

대조군과 교사군의 인구학적 특성과 음성에 영향을 줄 만한 사회적 요소들을 비교해 보면 연령, 성별, 직무 외 음성사용 량, 흡연력 및 음주력 등에 대해 두 군 사이에 유의한 차이가 없어 대조군의 선정에는 문제가 없었음을 알 수 있었다. 업무 이 외(출근 전과 퇴근 후)의 노래, 상담, 강의 및 기타 음성 사용시
간이 1 주일 동안 평균 1 시간 이상인 경우를 '업무 외 음성 사 용(excess voice usage)'으로 정의하여 조사하였다(Table 1).

음성장애지수 설문의 분석결과(Table 2), 기능적 영역에서는 '내 음성에 문제가 발생했을 경우, 나의 직업적인(경제적인) 문 제에 직접적인 영향을 미친다(F10)의 점수가 가장 높았고, 다음 으로 '사람들이 시끄러운 상황에서 내 말을 이해하는 데 어려워 한다(F2) 등 모두 5항목에서 대조군보다 유의하게 높은 점수 를 보였다. 신체적 영역에서는 '내 목소리는 저녁에 더욱 나빠진 다(P9)'와 '말하는 중간에 목소리가 약해진다(P10)' 등 10개 항 목 모두에서 점수가 높았다. 정서적 영역에서는 '목소리 문제로 인해 스트레스를 받는다(E5)'와 '목소리 문제로 인해 화가 난다 (E4)' 등 7개 항목에서 유의한 차이를 보였다. 설문 각 영역의 총점은 신체적>기능적>정서적 영역의 순이었고, 3 개 영역 모 두 대조군과 유의한 차이를 보였으나 $(p<0.05)$ 신체 및 기능적 영역 $(p \leq 0.001)$ 이 정서적 영역 $(p=0.024)$ 에 비해 더 뚜렷한 차 이를 보였다(Table 3). 음성장애지수의 총합을 기준(대조군 상위 $95 \%$ 이상, 즉 37점 이상)으로 조사한 주관적 음성장애의 빈도는 교사군 142명 중 32명(22.5\%)이었고 대조군 27명 중 1 명(3.7\%)으로 유의한 차이를 보였다 $(p<0.05)$ (Table 3).

음성 샘플의 음향학적 분석에서 jitter, shimmer, SNR은 두

Table 3. Comparison of $\mathrm{VHI}$ scores at three aspects and incidences of voice disorder judged by $\mathrm{VHI}$ total scores in the teachers and the control group

\begin{tabular}{|c|c|c|c|}
\hline & \multicolumn{2}{|c|}{ Median (mean \pm SD) } & \multirow{2}{*}{$\begin{array}{c}\text { Rank sum test } \\
\text { (p-value) }\end{array}$} \\
\hline & Teachers & Control & \\
\hline Functional & $8(8.408 \pm 5.78)$ & $2(3.926 \pm 4.29)$ & $<0.0001^{*}$ \\
\hline Physical & $10(10.13 \pm 7.09)$ & $3(4.741 \pm 6.11)$ & $0.0001^{*}$ \\
\hline Emotional & $4.5(6.789 \pm 7.39)$ & $1(3.185 \pm 4.76)$ & $0.0241^{*}$ \\
\hline \multirow[t]{2}{*}{ Total } & $22.5(25.32 \pm 18.4)$ & $6(11.85 \pm 14.2)$ & $<0.0001^{*}$ \\
\hline & & & $\begin{array}{c}\text { Chi-square test } \\
\text { ( } p \text {-value })\end{array}$ \\
\hline $\begin{array}{l}\text { Incidence of abnormal voice } \\
\text { judged by VHI total scores } \\
\text { (>95\% level of control's) }\end{array}$ & $32(22.5 \%)$ & $1(3.7 \%)$ & $0.0237^{*}$ \\
\hline
\end{tabular}

Table 4. Comparison of results of acoustic analysis between the teacher-group and the control-group

\begin{tabular}{|c|c|c|c|}
\hline & \multicolumn{2}{|c|}{ Median $($ mean \pm SD) } & \multirow{2}{*}{$\begin{array}{c}\text { Rank sum test } \\
\text { (p-value) }\end{array}$} \\
\hline & Teachers & Control & \\
\hline \multicolumn{4}{|l|}{ Acoustic analysis } \\
\hline Jitter & $0.2(0.238 \pm 0.16)$ & $0.2(0.457 \pm 0.71)$ & 0.5648 \\
\hline Shimmer & $2.2(2.543 \pm 1.31)$ & $2.2(2.293 \pm 0.74)$ & 0.7025 \\
\hline \multirow[t]{2}{*}{ SNR } & $20.9(20.52 \pm 4.85)$ & $20.9(21.05 \pm 2.44)$ & 0.6835 \\
\hline & & & $\begin{array}{c}\text { Chi-square test } \\
\text { (p-value) }\end{array}$ \\
\hline $\begin{array}{l}\text { Incidence of abnormal voice } \\
\text { judged by acoustic analysis } \\
\text { (jitter }>0.5 \text {, or shimmer }>3.0 \text {, or } S N R<10 \text { ) }\end{array}$ & 39 (27.5\%) & $4(14.8 \%)$ & 0.1666 \\
\hline
\end{tabular}


Table 5. Spearman correlation coefficient between voice handicap index and acoustic analysis

\begin{tabular}{lcccccc}
\hline & Jitter & Shimmer & SNR & Functional & Physical & Emotional \\
\hline Jitter & 1 & & & & & \\
Shimmer & $0.43^{*}$ & 1 & & & \\
SNR & $-0.444^{*}$ & $-0.868^{*}$ & 1 & & & \\
Functional & 0.008 & 0.012 & 0.005 & 1 & 1 & 1 \\
Physical & 0.055 & 0.084 & -0.036 & $0.716^{*}$ & $0.765^{*}$ & 1 \\
Emotional & -0.027 & 0.068 & 0.053 & $0.740^{*}$ & & \\
\hline
\end{tabular}

$* p<0.01$. SNR: signal-to-noise ratio

군 사이에 모두 유의한 차이를 보이지 않았다(Table 4). 음향분 석지표를 기준으로 비정상 판정을 받은 비율은 교사군이 142 명 중 39명(27.5\%), 대조군이 27명 중 4명(14.8\%)으로 교사군 에서 높게 나타났으나 통계적으로 유의한 차이는 아니었다(Table 4).

설문조사에서 얻은 음성장애지수와 음향분석지표의 상관 성 분석(correlation analysis) 결과, 각 설문영역 상호간에 그 리고 음향분석지표끼리는 높은 상관성을 보였으나, 음성장애 지수와 음향분석지표 사이의 상관성은 관찰할 수 없었다 $(p<$ 0.01)(Table 5).

\section{고 찰}

과거나 현재에 음성장애를 겪은 적이 없는 정상인 190명을 대상으로 시행한 음성장애지수 $(\mathrm{VHI})$ 총합의 정상범위는 평균 6.86(표준편차 9.88)으로 알려져 있다.) 본 연구 대조군의 VHI 총합의 중앙(median)값은 6 으로 이와 유사하며, 국내의 한 병원 에서 음성장애가 없는 직원을 대상으로 한 동일한 $\mathrm{VHI}$ 설문조 사에서 기능-신체-정서 영역의 평균치는 1.5-1.6-0.8점으로 본 연구의 중앙값 2-3-1점과 큰 차이가 없었다.) 본 연구에서 교사 군의 각 영역별 점수는 8-10-4.5이고 총합의 중앙값은 22.5로 병원을 방문한 후두질환 환자들의 결과와 비교해보면 인후두 역류질환 환자에서 조사된 23.5점과 유사하며 후두염(28.5 점)이나 성대결절 환자(38.2점)에는 미치지 못하는 점수였다.8)

고등학교 교사들과 언어치료사들을 대상으로 한 국내 연구 의 VHI-설문조사에서 교사들의 주관적인 음성장애 자각도 는 언어치료사들보다 유의하게 높은 것으로 나타났다. 특히, 교 사군에서 신체영역 점수가 가장 높고 정서영역 점수가 가장 낮 았다.') 이러한 경향은 성대질환으로 인해 병원을 방문하는 임 상환자들에서도 관찰되었다. ${ }^{7}$ 그러나 음성장애를 호소하는 가 수-성악가들에 대한 연구에서 가수들은 음성장애가 있는 일 반인과 음성장애지수 총합의 차이는 없으나 정서영역 점수가 기능적 점수보다 상대적으로 높아 음성 변화에 대해 심리적 으로 보다 민감한 가수로서의 특성을 보였다.9) 본 연구 결과에 서 정서 영역 점수가 다른 영역 점수보다 낮았던 점은 교사들
이 대개 자신들의 음성문제를 신체적 장애로써 더 인식하며 심리적으로는 둔감하거나 무시하려는 경향이 있기 때문이라고 해석할 수 있다. 이는 음성을 고유의 직업 수단으로 전문적으 로 세심하게 관리하고 있는 가수들에 비해 음성 문제의 해결에 더 적극적이지 못할 가능성을 시사한다.

교사, 목사 및 전화교환수들의 음성에 대한 연구에서, 목사 는 음성피로>발성통>애성>발성범위 감소의 순으로 증상을 느끼며 교사도 음성피로>발성범위 감소>발성통>애성으로 유사한 증상을 호소한다고 하였다. 이 연구에서 목사군과 전 화교환수들의 평균 jitter와 shimmer는 대조군보다 유의하게 높았으나, 남자교사들은 대조군과 유의한 차이가 없었다. ${ }^{10}{ }^{10}$ 본 연구에서도 교사군과 대조군 사이에 jitter, shimmer, SNR의 유의한 차이는 관찰되지 않았다.

교사군 1243 명과 비교사군 1288 명을 대상으로 한 전화 설 문조사연구에서 애성, 음성피로, 대화와 노래할 때의 장애, 발 성곤란, 노래음역 감소, 음성과 관련된 불편감, 발성을 위한 노 력 필요, 단조로운 음성, 만성적인 목의 건조감 및 통증, 잦은 헛기침, 음성 떨림 등 주관적 장애를 기준으로 비교한 결과, 비 교사군(6\%)에 비하여 교사군(15\%)에서 음성문제가 더 많이 발 생하고 있다고 보고한 바 있다. ${ }^{2}$

본 연구에서 음성장애지수 총합을 기준으로 조사한 주관적 음성장애의 빈도는 교사군에서 $22.5 \%$, 대조군 $3.7 \%$ 로 유의하 게 교사군에서 높았으나 $(p=0.0237$, Chi-square test), 객관적 인 음향분석 지표로 판정한 객관적 음성장애의 빈도는 교사군 $27.5 \%$, 대조군 $14.8 \%$ 로 유의한 차이가 없었다 $\left(p=0.1666, \mathrm{Chi}^{-}\right.$ square test).

설문조사의 결과와 음향분석 결과 사이의 상관성을 살펴보 면, 설문결과에 따라 주관적 음성장애로 판정된 교사 32 명 중 객관적 기준(음향분석지표)에서도 비정상 결과를 보인 교사의 수는 단지 5 명으로 두 평가방식의 일치율은 $15.6 \%$ 에 지나지 않았다. 외국의 보고에서도 교사들에게서 보고되는 음성 문제 의 발생 빈도는 객관적 진단도구에 의한 경우에는 $4.4 \%$ 에 지나 지 않으나 자가보고(self-report)에서는 90\%에 이르는 등 평가 방식에 따라 빈도의 차이가 아주 심한 것으로 알려져 있다. ${ }^{11,12)}$ 음성장애 평가방식의 유효성에 대해서는 향후 심도 있는 연구 
가 반드시 필요할 것으로 생각된다. 객관적 음향분석지표들(jitter, shimmer, SNR)은 음성 발생에 관련된 일부 성분만을 평 가할 따름이고, 음성장애로 인한 전반적 문제를 평가하지는 못 하며, 더욱이 동일한 성대질환이라 하더라도 음성을 직업적으 로 사용하는 경우(예를 들면 교사군)와 그렇지 않은 경우에 따 라 일상 생활과 직업 및 사회활동에 미치는 영향과 의미에 큰 차이가 있으므로 주관적으로 느끼는 장애의 정도를 평가하기 위해 음성장애지수와 같은 자각적 설문조사를 함께 시행하는 것이 꼭 필요하다는 주장이 있다. ${ }^{13)}$ 그러나 jitter, shimmer, SNR 등을 $\mathrm{VHI}$ 설문의 총점 및 개별 문항 점수와 비교했을 때 상관 성이 적다는 연구결과가 일관되게 발표되어 왔고, 본 연구결과 에서도 음향학적 지표들과 음성장애지수(VHI)의 각 영역별 총 점을 비교해본 결과 상호간의 상관성이 없었다. ${ }^{14)}$ 본 연구에 사용 된 음성장애지수(VHI) 설문은 2002년 미 보건국의 건강관리 연구 및 질 향상 기구(Agency for Health Care Research and Quality)에서 그 유효성과 신뢰도를 인정한 바 있는 유효한 음 성 관련 평가도구로 알려져 있다. 그러나 주관적 설문이 갖는 본 질적인 문제점으로서 음성피로를 받아들이는 개인의 감수성 차이, 정서적 배경 그리고 설문 결과에 기대하는 이차적 이득 등의 여러 요소가 있으므로 이를 감안하여 결과를 해석할 필 요가 있다.

본 연구에서 시행한 2초간의 녹음 음성샘플에 대한 제한적 분석 결과만으로 주관적 음성장애를 반영하는 것은 불충분하 다고 생각된다. 비교적 긴 문장을 읽은 샘플을 음성 전문가가 듣고 지각적 평가를 하거나 음성피로를 유발하는 최소 음성 사 용량 측정하는 방법 등을 향후 연구에서 도입할 만하다고 생 각된다. 또한 교사들의 연령, 성별, 근무경력, 대상 학교 및 학 년, 수업 중 마이크 사용여부 등의 변수를 고려한 심층적 분석 도 가능하였으나, 근무환경, 업무성격 및 업무량, 개인 신상정 보와 관계된 어떤 차별적 요소를 포함하는 결과도 공표하지 않 기로 대상 선생님들과 합의한 바에 따라 본 연구에서 발표하지 못하는 것은 아쉬운 부분이다. 학교를 방문하여 조사할 수 밖
에 없었던 구조적 한계, 임상적인 음성질환의 유무 판정을 받게 되는 것에 대한 선생님들의 심리적인 저항감, 그리고 연구의 주 목적이 주관적 장애와 음성의 특성조사에 국한되었던 이유들 로 인해 후두 내시경을 이용한 임상적 관찰이 이루어지지 못한 점도 본 연구의 한계점으로 생각된다.

\section{REFERENCES}

1) Verdolini K, Ramig LO. Review: occupational risks for voice problems. Logoped Phoniatr Vocol 2001;26(1):37-46.

2) Roy N, Merrill RM, Thibeault S, Parsa RA, Gray SD, Smith EM. Prevalence of voice disorders in teachers and the general population. J Speech Lang Hear Res 2004;47(2):281-93.

3) Lee OB, Jung OL. Voice handicap index of professional voice users. 7th Conference of Korean Speech Science;2001. p.207-11.

4) Jacobson BH, Johnson A, Grywalski C, Silbergleit A, Jacobson G, Benninger MS. The Voice Handicap Index (VHI): development and validation. Am J Speech Lang Pathol 1997;6(3):66-70.

5) Kim J, Lim SE, Park SY, Choi SH, Choi JN, Choi HS. Validity and reliability of Korean-Version of voice handicap index and voice-related quality of life. J Korean Soc Speech Sci 2007:14(3):111-25.

6) Arffa RE, Krishna P, Gartner-Schmidt J, Rosen CA. Normative Values for the Voice Handicap Index-10. J Voice. In press 2011.

7) Choi DY, Choi SM, Lim GC, Nam SY. Usefulness of Voice Handicap Index in patients with hoarseness. Korean J Otolaryngol-Head Neck Surg 2002;45(7):706-10.

8) Rosen CA, Murry T. Voice handicap index in singers. J Voice 2000; 14(3):370-7.

9) Kim JM, Park HW, Lee SW, Park HS, Kim SY, Yoo SJ, et al. Voice analysis of chronic \& daily voice burden in professionals. J Korean Soc Logopedics Phoniatrics 2001;12(1):17-21.

10) Jin SM, Park SO, Lee JW, Lee KC, Lee YB. Acoustic and stroboscopic characteristics in teachers, clergies and telephone operators. J Korean Soc Logopedics Phoniatrics 1998;9(1):53-8.

11) Lejska V. [Occupational voice disorders in teachers]. Prac Lek 1967;19(3):119-21.

12) Marks JB. A comparative study of voice problems among teachers and civil service workers. [dissertation] Minneapolis: University of Minesota;1985.

13) Woo P. Quantification of videostrobolaryngoscopic findings--measurements of the normal glottal cycle. Laryngoscope 1996;106(3 Pt 2 Suppl 79):1-27.

14) Wheeler KM, Collins SP, Sapienza CM. The relationship between VHI scores and specific acoustic measures of mildly disordered voice production. J Voice 2006;20(2):308-17. 